\title{
Effect of Inlet Conditions on Taylor Bubble Length in Microchannels
}

\author{
Nan SHAO, Asterios GAVRIILIDIS, Panagiota ANGELI * \\ *Corresponding author: Tel.: +44 (0)20 7679 3832; Fax: +44 (0)20 7383 2348; \\ Email: p.angeli@ucl.ac.uk \\ Department of Chemical Engineering, University College London, UK
}

\begin{abstract}
The effect of inlet conditions on the frequency and size of the bubbles that form during gas-liquid Taylor flow in microchannels is investigated in this paper. Three different inlet configurations, T-, Y- and Mjunction as well as three test channels with hydraulic diameters $0.345 \mathrm{~mm}, 0.577 \mathrm{~mm}$ and $0.816 \mathrm{~mm}$ were used. The test fluids were nitrogen and water or octane, that have different surface tension. It was found that bubble length increased with increasing gas flowrate, gas inlet size and liquid surface tension and decreasing liquid flowrate. From the different inlet configurations, the $\mathrm{M}$-junction resulted in the largest bubbles and the Y-junction in the smallest ones particularly at low liquid flowrates. The experimental bubble sizes were tested against a number of literature correlations but the agreement was not very good. Two new correlations were developed for the T- and the Y-junctions to calculate the unit cell (one bubble and one slug) frequency from which the bubble length can be found. Bubble lengths predicted from these correlations were in good agreement with experimental ones obtained from video recordings.
\end{abstract}

Keywords: Two-phase flow, Taylor flow, Bubble length, Inlet configuration

\section{Introduction}

Gas-liquid two-phase flow in microchannels has been the subject of increased research interest in the past few years. It is encountered in many important applications, such as miniature heat exchangers, microscale process units, research nuclear reactors, materials processing and thin film deposition technology, biotechnology systems and potential space applications. One of the most common flow patterns that appear is Taylor flow that consists of elongated bubbles with equivalent diameter usually many times that of the channel diameter, separated by liquid slugs. The bubbles adopt a characteristic capsular shape and can either completely or nearly completely fill the channel cross section where at most a thin liquid film separates them from the channel wall. The sizes of the bubbles and liquid slugs are very important for determining pressure drop and mass transfer rates during Taylor flow. A number of correlations have been suggested in the literature for the prediction of bubble size (e.g. Kreutzer, 2003; Garstecki et al., 2006; Qian and Lawal, 2006). However, the inlet configuration that has been found to play an important role is not usually taken into account. Although bubble and slug sizes can be calculated via Computational Fluid Dynamics (CFD) simulations (e.g. Shao et al., 2008) for different test section configurations, the computations tend to be expensive because of the 3D models required for the non-circular channels normally encountered in microapplications. Experiments can provide valuable information on the variation of bubble and slug sizes under different conditions and inlet channel geometries.

\section{Experimental set up}

Taylor bubble and slug sizes were measured experimentally in acrylic channels with a trapezium cross section using nitrogen and water or octane as test fluids. The test sections were fabricated in-house using engraving (Roland EGX-400 Flatbed Engraving Machine) on transparent acrylic sheets. Three different channel sizes (with hydraulic diameters, $d_{H}=0.345 \mathrm{~mm}, 0.577 \mathrm{~mm}$ and $0.816 \mathrm{~mm}$ ) and three inlets with $\mathrm{T}, \mathrm{Y}$ and $\mathrm{M}$ configurations were studied (Fig. 1). Three different gas inlet sizes were used, $d_{H, \text { Gin }}$, $0.345 \mathrm{~mm}, 0.577 \mathrm{~mm}$ and $0.816 \mathrm{~mm}$, while the 


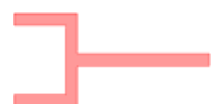

(a)

Fig. 1. Inlet configurations used in the study. (a) T-junction; (b) Y-junction; (c) M-junction.

liquid inlet size was $d_{H, L i n}=0.577 \mathrm{~mm}$. The gas phase was nitrogen and the liquid phase was either water or octane that have different surface tension, $\sigma$ (water: $0.07226 \mathrm{~Pa} \mathrm{~s}$, octane: $0.02149 \mathrm{~Pa}$ s). The nitrogen flow was supplied from a gas cylinder and regulated with a Bronkhorst EL-FLOW F-110C mass flow controller with a range $0.01-1 \mathrm{ml} / \mathrm{min}$. The liquid was introduced by using a MiliGat pump $(0-6 \mathrm{ml} / \mathrm{min})$. Bubble formation was captured with a high-speed video system Kodak HS 4540, which can record between 30 and 4500 frames per second (fps) in full frame mode and 9000-40500 fps in segmented frame mode. Data were collected in a PC and analyzed. The unit cell (one bubble and one slug) or bubble frequencies were obtained by counting the number of bubbles within a time period. From the bubble frequency bubble length was calculated (see Liu et al., 2005). In addition, bubble lengths were also measured in some cases directly from the recorded images using the image analysis software Aequitas. About 5-80 bubbles were then used to calculate an average in each case.

\section{Experimental results}

\subsection{Effect of gas and liquid flowrates}

Gas and liquid flowrates have been found to affect significantly the size of the Taylor bubbles at Capillary numbers, $\mathrm{Ca}$, less than 1.3E-3 (for discussion see Shao et al., 2008). The effect of gas and liquid flowrates is investigated in the current set up for a larger range of $\mathrm{Ca}$ up to $1.1 \mathrm{E}-2$ and is shown in Fig. 2 for a test section with $d_{H}=0.577 \mathrm{~mm}$ and gas inlet equal to $0.577 \mathrm{~mm}$ ). As can be seen in Fig. 2a, bubble length increases with increasing gas flowrate, $Q_{G}$, and decreasing liquid flowrate, $Q_{L}$. In addition, the frequency of the unit cell, $f_{u c}$, also increases with increasing gas or liquid flowrates (Fig. 2b), resulting in shorter units cells.

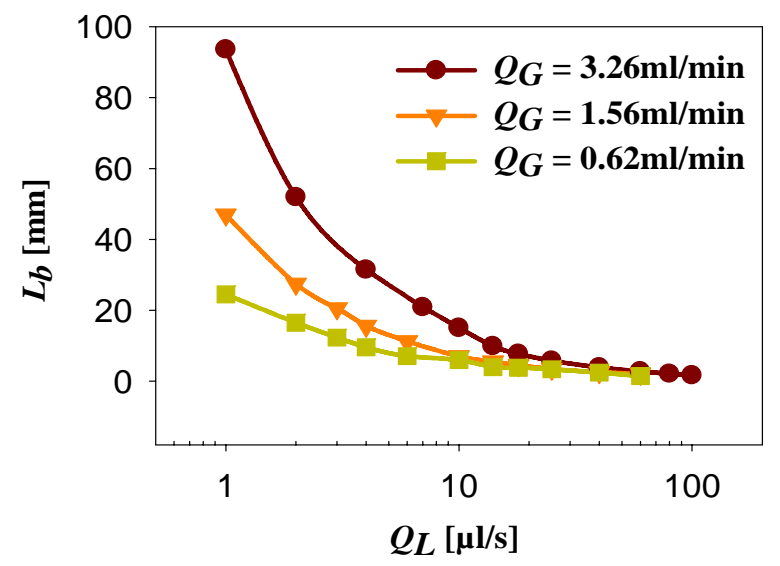

(a)

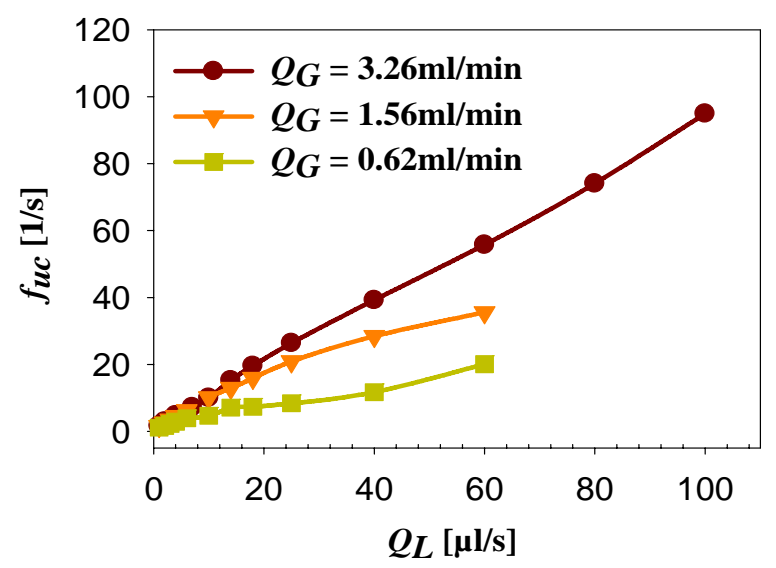

(b)

Fig. 2. Effects of gas and liquid flowrates on (a) bubble length and (b) unit cell frequency. $d_{H}=0.577 \mathrm{~mm}, d_{H, G i n}=0.577 \mathrm{~mm}$, liquid phase: water, inlet configuration: $\mathrm{Y}$-junction.

\subsection{Effect of surface tension}

To investigate the effect of surface tension, experiments were carried out with both water and octane as the liquid phase. Longer bubbles are generated in the nitrogen-water system that has higher surface tension (Fig. 3) The increased attaching effect of surface tension force in water at the test section inlet during bubble formation explains the difference. Similar trends were found for the other channel sizes used.

\subsection{Effect of gas inlet size}

Three gas inlet sizes were investigated and their effect on bubble length is shown in Fig.4. 


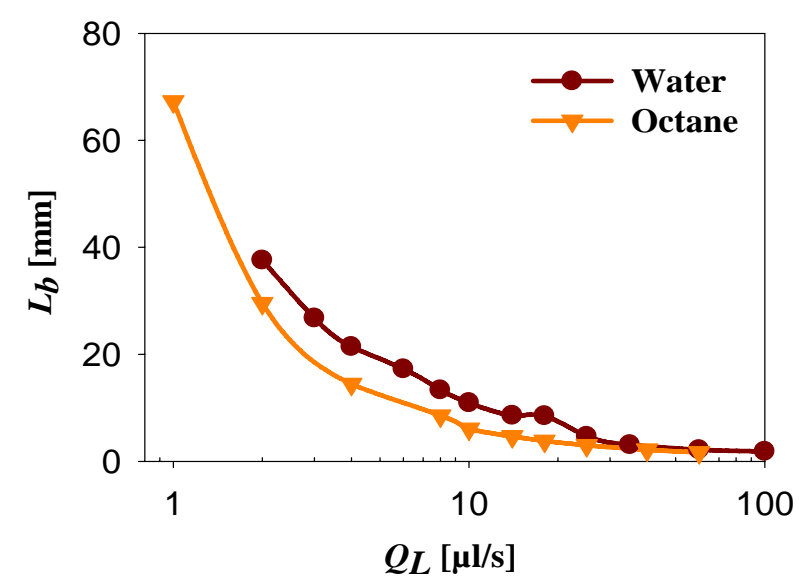

Fig. 3. Effect of liquid phase on bubble length. $Q_{G}=1.56 \mathrm{ml} / \mathrm{min}, d_{H}=0.577 \mathrm{~mm}, d_{H, \text { Gin }}=$ $0.577 \mathrm{~mm}$, inlet configuration: T-junction.

Bubble length is found to increase with gas inlet size, in agreement with CFD simulations (Shao et al. 2008). Gas inlet size can affect bubble formation in two ways: for the same gas flowrate the gas flux in a large inlet, which has a detaching effect, decreases; in addition, the increased periphery of a large inlet increases the surface tension force which has an attaching effect. Both help to extend the bubble formation time and thus its size. The rate of bubble length increase however, is reduced as the inlet size increases, probably because the effect of surface tension is weakened at larger dimensions.

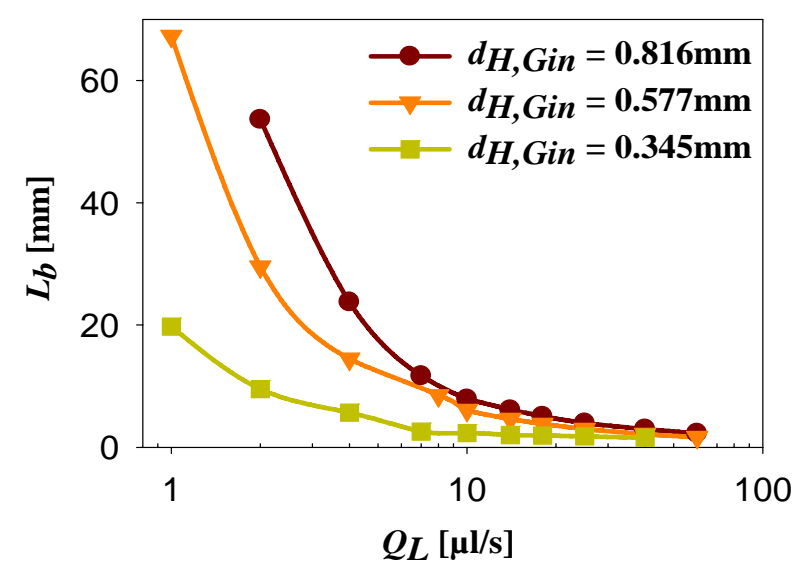

Fig. 4. Effect of gas inlet size on bubble length. $Q_{G}=1.56 \mathrm{ml} / \mathrm{min}, d_{H}=0.577 \mathrm{~mm}$, liquid phase: octane, inlet configuration: $\mathrm{T}$ junction.

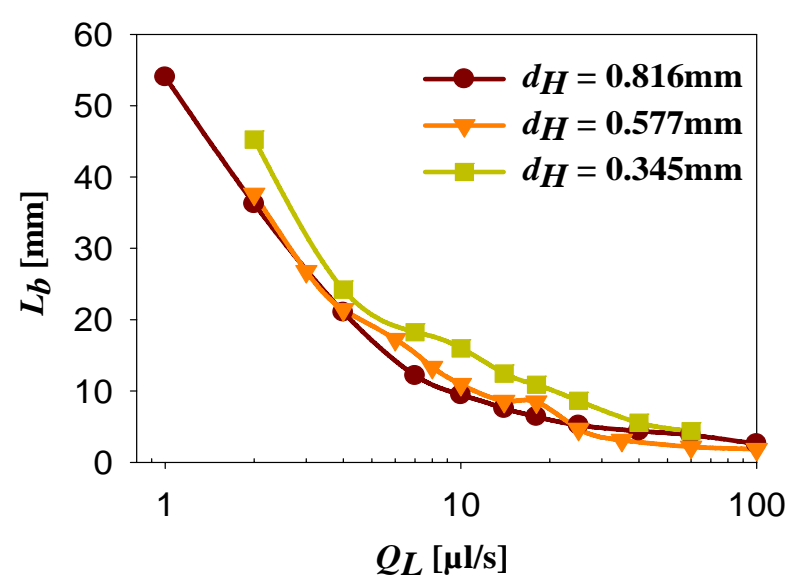

(a)

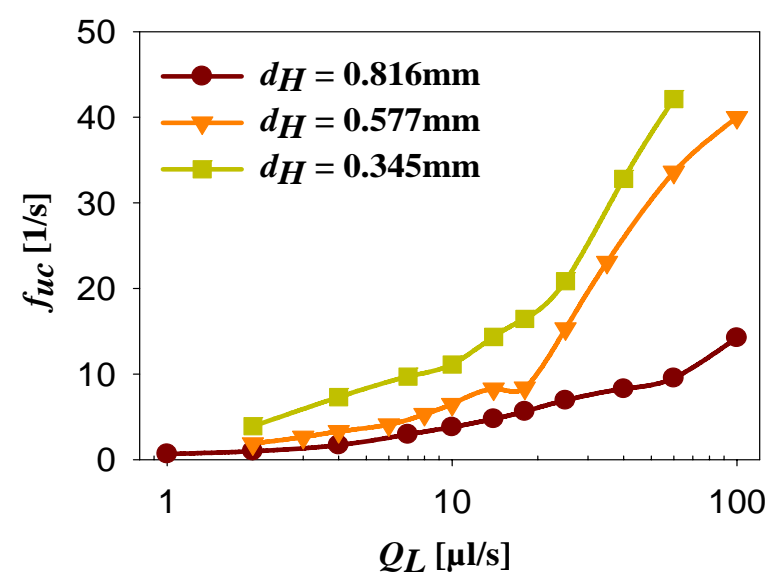

(b)

Fig. 5. Effect of test channel size on (a) bubble length and (b) unit cell frequency. $Q_{G}=$ $1.56 \mathrm{ml} / \mathrm{min}, d_{H, \text { Gin }}=0.577 \mathrm{~mm}$, liquid phase: water, inlet configuration: T-junction.

\subsection{Effect of test channel size}

Bubble lengths are found to be similar in channels of different size when the same inlet design is used (Fig. 5a). A further examination reveals that the unit cell frequency is higher in the small channels compared to the large ones (Fig. 5b), which means that smaller bubble volumes are produced in the small channels. This is because in small channels bubbles are confined by the channel walls which limit their cross sectional growth during formation at the inlet. At the same time the liquid shear on the bubbles is increased due to the increased liquid superficial velocity in the small channels compared to the large ones for the same flowrate. Both these phenomena contribute to an earlier detachment of bubbles in the small 
channels compared to the large ones. The above observations apply to the octane system as well.

\subsection{Effect of gas-liquid contacting}

The bubble lengths for the three different inlet configurations for $d_{H}=0.577 \mathrm{~mm}$ and for water and octane are presented in Fig. 6 for gas inlet equal to $0.345 \mathrm{~mm}$ and in Fig. 7 for gas inlet equal to $0.816 \mathrm{~mm}$. In general, the largest bubbles are produced in the M-Junction, followed by those in the $\mathrm{T}$-junction while the smallest bubbles form in the Y-junction. According to Qian and Lawal (2006) bubble size would depend on the quality of the mixing between the two fluids at the channel inlet;

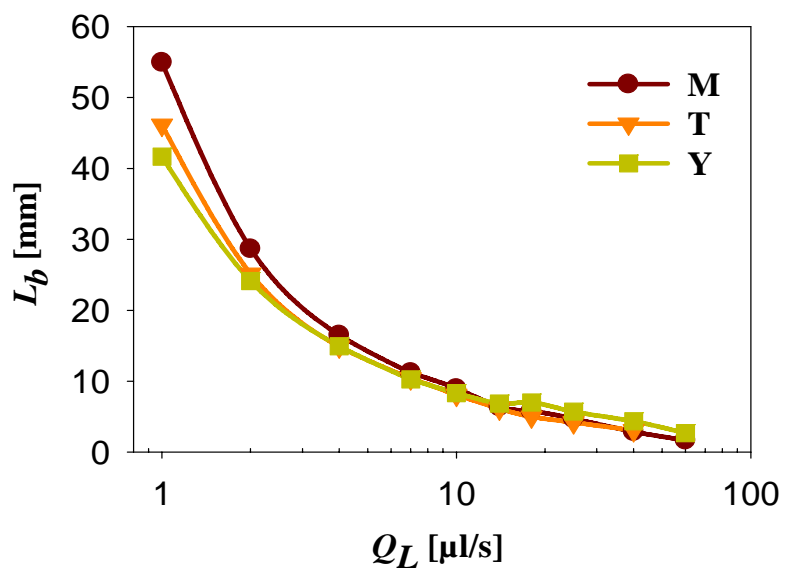

(a) water

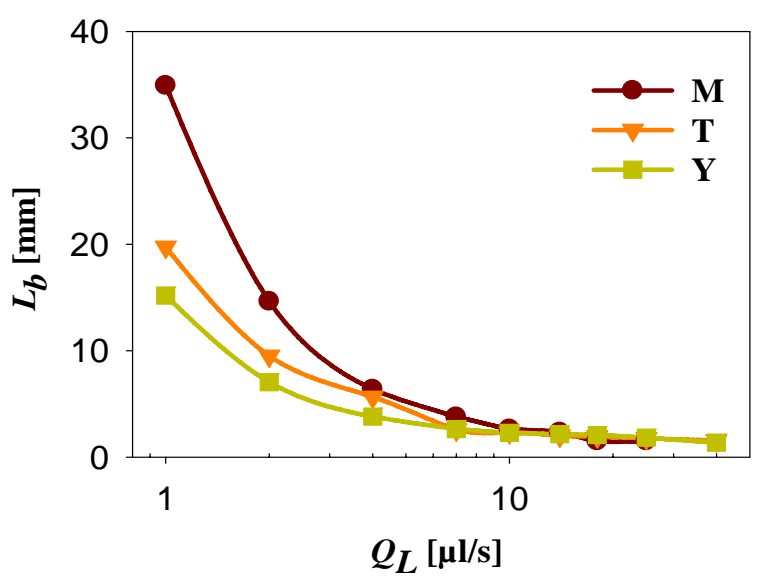

(b) octane

Fig. 6. Bubble lengths under different gasliquid contacting configurations for $d_{H, \text { Gin }}=$ $0.345 \mathrm{~mm}$ and (a) water and (b) octane. $Q_{G}=$ $1.56 \mathrm{ml} / \mathrm{min}, d_{H}=0.577 \mathrm{~mm}$. Mixing volume at inlet is: M-junction: $0.247 \mu \mathrm{l}$, T-junction: $0.101 \mu 1$, Y: junction: $0.064 \mu 1$. good mixing would result in small bubbles. The different inlets used here have different volumes for the mixing of the two phases; better mixing is expected when the mixing volume is small. The M-inlet with the largest mixing volume would be expected to create large bubbles, while the Y-inlet with the smallest volume will create small bubbles. The differences between the inlets become less significant as the bubble size decreases with increasing liquid flowrate. Similar results were found for the intermediate gas inlet size $(0.577 \mathrm{~mm})$.

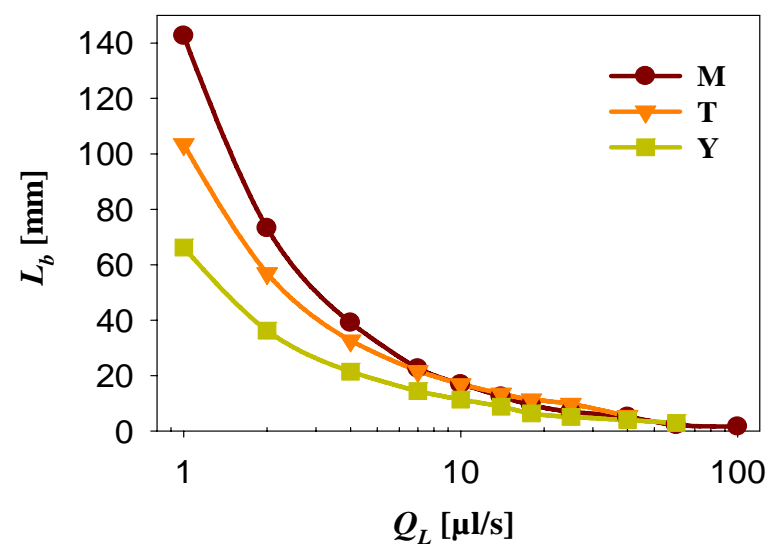

(a) water

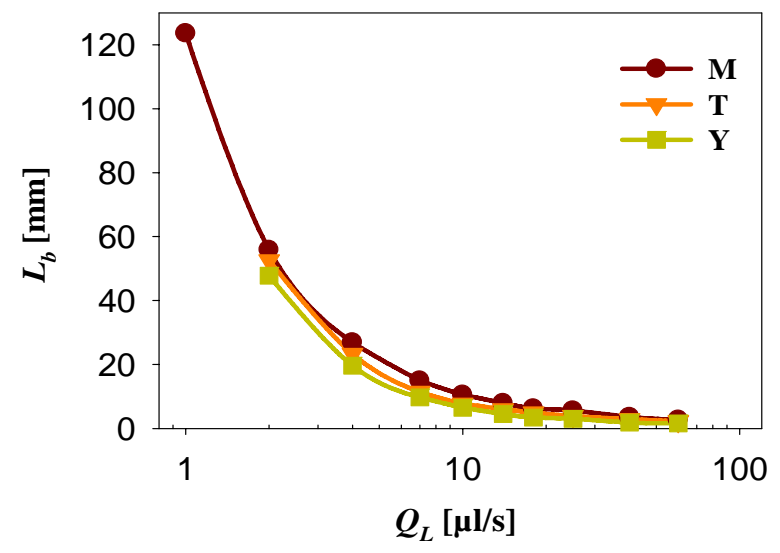

(b)octane

Fig. 7. Bubble lengths under different gasliquid contacting configurations for $d_{H, \text { Gin }}=$ $0.816 \mathrm{~mm}$ and (a) water and (b) octane. $Q_{G}=$ $1.56 \mathrm{ml} / \mathrm{min}, d_{H}=0.577 \mathrm{~mm}$. Mixing volume at inlet is: M-junction: $1.444 \mu 1$, Y-junction: $0.483 \mu$ l, T-junction: $0.475 \mu l$.

\subsection{Prediction of bubble length}

For the application of microreactors operating in Taylor flow it is important to be able to 
predict bubble lengths from information available on channel geometry and operating conditions. A number of correlations have been suggested in the literature (see Section 1). Previous work (Shao et al., 2008) indicated that correlations including phase fraction predict bubble lengths obtained from CFD simulations better than those which did not account for phase fraction. Therefore the correlations developed by Kreutzer (2003), Qian an Lawal (2006) and Garstecki et al. (2006), that include phase fraction, are compared against the experimental data in Fig. 8. Only data recorded from the T-junction inlet are used. In addition, data at very high or very low liquid flowrates are not included because only a few experiments were carried out at these conditions. It can be seen from Fig. 8 that in most cases the correlation from Garstecki et al. (2006) underpredicts the results probably because it applies to low $\mathrm{Ca}$ flows where bubbles form through the squeezing mechanism. The Qian and Lawal (2006) equation performs the best among the three probably because it includes the effect of surface tension. The widely scattered results, however, suggest that none of these correlations works well for the current system since the effect of gas inlet size is not taken into account.

To develop a correlation for the current system the unit cell frequency is used, because it is the parameter that is measured experimentally. The unit cell frequency or bubble length was found to be mainly affected by gas and liquid flowrates, surface tension, gas inlet size and main channel size. Although the inlet configuration was important, it cannot be easily quantified and different correlations are developed for the $\mathrm{T}$ - and $\mathrm{Y}$-junctions respectively, because they are more commonly encountered in microreactor applications compared to the M-junction.

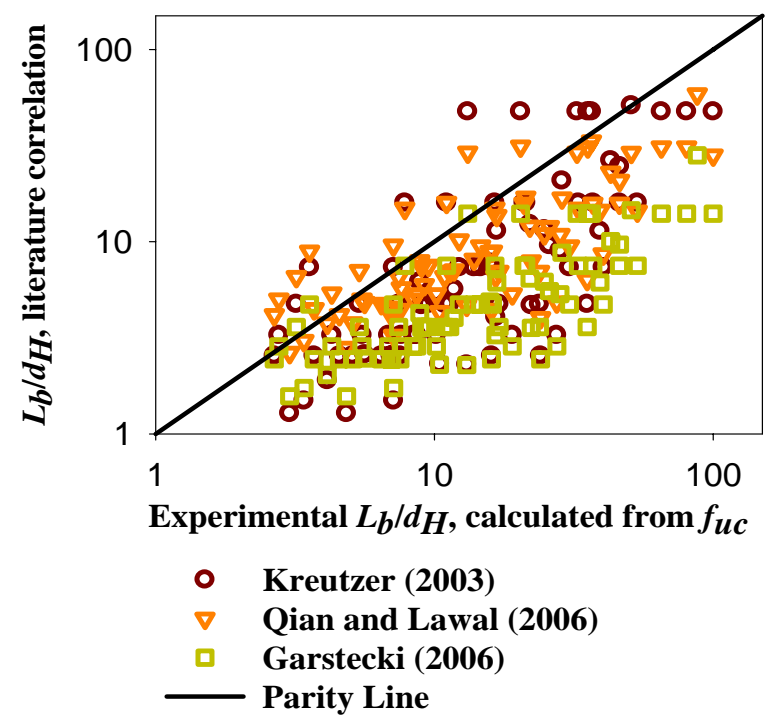

Fig. 8. Comparison of experimental bubble lengths (derived from unit cell frequency) against those calculated from literature correlations. $Q_{G}=0.62-3.26 \mathrm{ml} / \mathrm{min}, Q_{L}=2$ $18 \mu \mathrm{l} / \mathrm{s}, d_{H}=0.345-0.816 \mathrm{~mm}, d_{H, \text { Gin }}=0.345-$ $0.816 \mathrm{~mm}$, liquid phase: water and octane, inlet configuration: T-junction.

The unit cell frequency is found to be correlated best with the following parameters: homogeneous liquid fraction, $\varepsilon_{L} \quad\left(\varepsilon_{L}=\right.$ $\left.Q_{L} /\left(Q_{G}+Q_{L}\right)\right)$, gas inlet cross sectional area, $A_{\text {Gin }}$, channel cross sectional area, $A_{C}$ and capillary number, $\mathrm{Ca}$. Since less data was available for the Y-junction test section on the effect of main channel size, the same exponential factor for $A_{C}$ is used as that for the T-junction. The unit cell frequency correlations for the $\mathrm{T}$ - and $\mathrm{Y}$-junctions are given below:

\section{Eq. (1): Unit cell frequency for T-junction}

$f_{u c, T}=4.389 \times 10^{4} \varepsilon_{L}{ }^{0.694} A_{G i n}{ }^{-0.534} A_{C}{ }^{0.453} C^{1.294}$

\section{Eq. (2): Unit cell frequency for Y-junction}

$f_{u c, Y}=2.97 \times 10^{4} \varepsilon_{L}{ }^{0.821} A_{\text {Gin }}{ }^{-0.355} A_{C}{ }^{0.453} C^{0.984}$

From the unit cell frequency bubble length can be calculated according to Eq. (3), as shown by Liu et al. (2005): 
Eq. (3): bubble length from unit cell frequency

$$
L_{b}=\left(U_{b} / f_{u c}\right) \varepsilon_{G}-2 d_{b}
$$

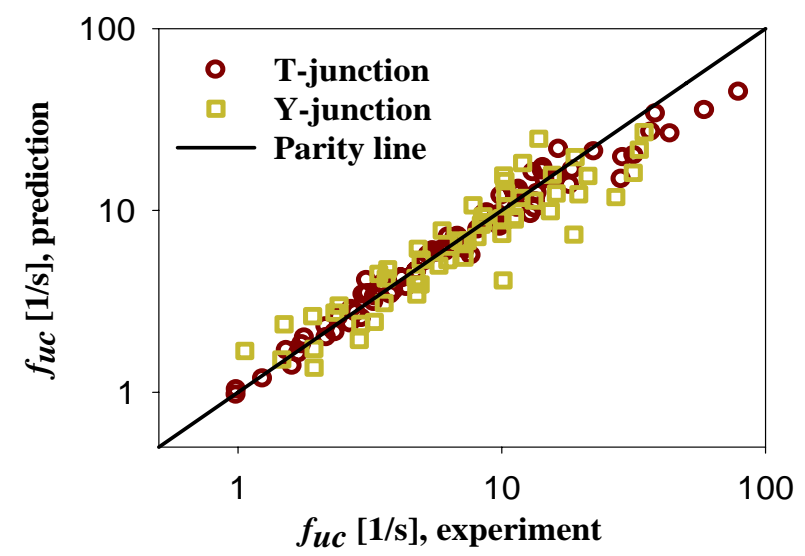

Fig. 9. Comparison between experimental unit cell frequencies and predicted ones from Equations (1) and (2).

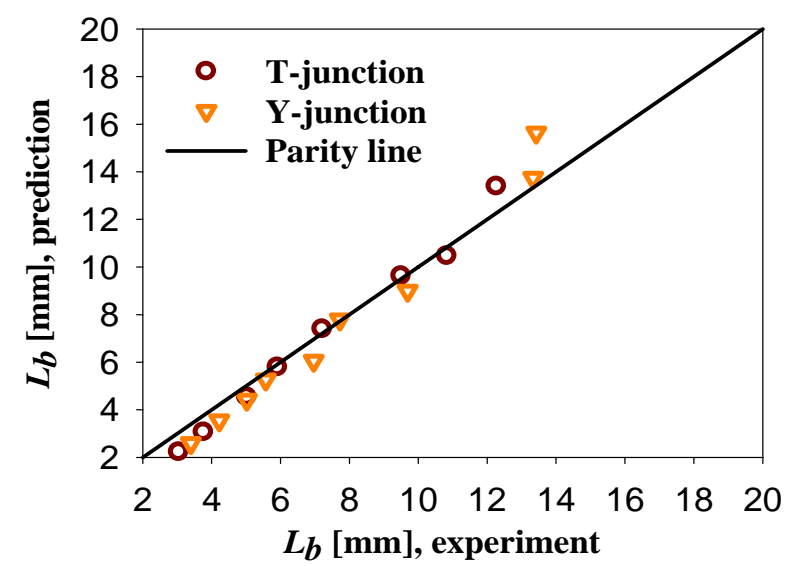

Fig. 10. Comparison of experimental bubble lengths obtained from recorded images and predicted lengths calculated using the correlations for the unit cell frequencies. $Q_{G}=$ $0.62-3.26 \mathrm{ml} / \mathrm{min}, Q_{L}=2-18 \mu \mathrm{l} / \mathrm{s}, d_{H}=0.345-$ $0.816 \mathrm{~mm}, d_{H, \text { Gin }}=0.345-0.816 \mathrm{~mm}$, liquid phase: water and octane.

The unit cell frequency predictions are plotted against the experimental data in Fig. 9. The standard deviation of bubble frequency for the $\mathrm{T}$ - and $\mathrm{Y}$-junctions is $11 \%$ and $19 \%$ respectively. With the $\mathrm{Y}$-junction it was seen that bubbles break up away from the inlet, further inside the channel at locations which varied. This may have contributed to the larger deviation with this inlet compared to the T- junction. The bubble lengths predicted from the above correlations are found to be in good agreement with bubble lengths measured from recorded images (Fig. 10). Reasonable agreement is also found when the correlation for the T-junction is used to predict the simulated bubble lengths by Qian and Lawal (2006).

\section{Conclusions}

Bubble lengths were obtained during gasliquid Taylor flow in microchannels using different inlet geometries. It was found that the bubble length increased with increasing gas flowrate, gas inlet size and liquid surface tension and decreasing liquid flowrate. From the different inlets used the M-junction, that had the largest mixing volume, produced longer bubbles while the Y-junction with the smallest mixing volume gave shorter bubbles. Available literature correlations did not predict satisfactorily the experimental bubble lengths. Two correlations were developed, one for the $\mathrm{T}$ - and the other for the $\mathrm{Y}$-junction, to predict unit cell frequencies from which bubble lengths can be estimated. The correlations were found to predict well experimental bubble lengths obtained from video images as well as the data by Qian and Lawal (2006).

\section{Nomenclature}

A Channel cross-sectional area, $\mathrm{m}^{2}$

$d \quad$ Internal or hydraulic diameter, $\mathrm{m}$

$f \quad$ Frequency, $1 / \mathrm{s}$

$L \quad$ Length, $\mathrm{m}$

$Q \quad$ Volumetric flowrate, $\mathrm{m}^{3} / \mathrm{s}$

$U$ Velocity, $\mathrm{m} / \mathrm{s}$

\section{Greek Symbols}

$\varepsilon \quad$ Volume fraction of fluid, -

$\mu \quad$ Dynamic viscosity, $\mathrm{Pa} \mathrm{s}$

$\sigma \quad$ Surface tension, $\mathrm{Pa} \cdot \mathrm{s}$

Dimensionless numbers

$\mathrm{Ca}$ Capillary number, $\mu_{L} U_{b} / \sigma$

\section{Subscripts}

$b \quad$ Bubble

C Channel or capillary 


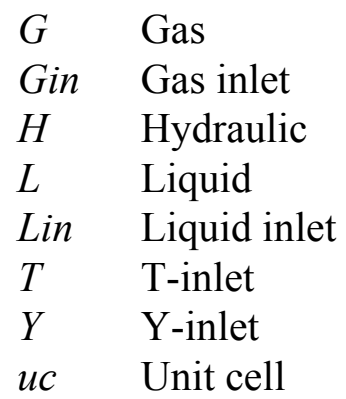

\section{References}

Garstecki P., Fuerstman M.J., Stone H.A., Whitesides G.M., 2006. Formation of droplets and bubbles in a microfluidic T-junction scaling and mechanism of break-up. Lab Chip, 6, 437-446.

Kreutzer M.T., 2003. Hydrodynamics of Taylor flow in capillaries and monolith reactors. $\mathrm{PhD}$ Thesis, Technical University of Delft.

Liu H., Vandu C.O., Krishna R., 2005. Hydrodynamics of Taylor flow in vertical capillaries: flow regimes, bubble rise velocity, liquid slug length and pressure drop. Ind. Eng. Chem. Res.44, 4884-4897

Qian D., Lawal A., 2006. Numerical study on gas and liquid slugs for Taylor flow in a Tjunction microchannel. Chemical Engineering Science 61, 7609-7625.

Shao N., Salman W., Gavriilidis A., Angeli P., 2008. CFD simulations of the effect of inlet conditions on Taylor flow formation. Int. J. Heat Fluid Flow 29, 1603-1611. 